\title{
Mammographic breast density patterns among a group of women in sub Saharan Africa
}

\author{
${ }^{*}$ Galukande $\mathrm{M}^{1}$, Kiguli-Malwadde $\mathrm{E}^{2}$
}

1. Surgery department, College of Health Sciences, Makerere University, Uganda

2. Radiology department, College of Health Sciences, Makerere University, Uganda

\begin{abstract}
Introduction: Mammographic breast density is a measure of parenchymal breast patterns on film and in part a marker of cumulative exposure to oestrogen. The risk of breast cancer for women with increased density is up to six fold more than in women with less dense tissues. The pattern of mammographic breast density among Ugandan women is not known. Objective: To establish these as a contribution to baseline data..

Methods: A cross sectional descriptive study that enrolled women presenting for mammography at the national referral hospital radiology department. Breast densities were scored using the BI-RADS categories. IRB approval was obtained.

Results: Of the 190 women enrolled, 178 were scored, of those scored 10 (5.3\%) had extremely dense breasts (grade IV) and 39 (20.5\%) had heteregenous ones (grade III). The rest 129 (67.9\%) had scattered fibroglandular or fat densities (Grades I \& II). Most of the women were young $45.8 \pm 12.5$ years The majority had normal or benign mammographic findings and all were non pregnant.

Conclusion: Mammographic densities in this Ugandan population appear to be of low grade. The pattern established here is markedly different from findings in other studies that indicated much higher proportions for high dense tissues in other races. Mammographic interpretation of films could therefore be easier.
\end{abstract}

Key words: mammography, breast, density

African Health Sciences 2012; (4): 422 - 425 http://dx.doi.org/10.4314/ahs.v12i4.4

\section{Introduction}

Mammographic breast density is a measure of parenchymal breast patterns on $\mathrm{x}$-ray film and in part a marker of cumulative exposure to oestrogen ${ }^{1}$. The appearance of the breast parenchyma at mammography is determined by the fat component which appears lucent in contrast to the epithelium and stroma which appear dense. This appearance varies among women because of the difference in tissue composition and differences in radiographic attenuation properties of the three components; fat, stroma and epithelium. Increased mammographic breast density is also a moderate independent risk factor for breast cancer, with findings of published studies showing a positive association ${ }^{2,3,4}$. This has

\footnotetext{
*Corresponding author:

Dr. Moses Galukande

Department of Surgery

College of Health Sciences

Makerere University

P. O. Box 7072

Kampala, Uganda

Email: mosesg@img.co.ug
}

been documented elsewhere and it did not change whether quantitative or qualitative assessment was done. Increased breast density is associated with lower sensitivity of mammography ${ }^{5}$. The risk of breast cancer for women with increased breast density in most of these studies is 4-6 times that for women with less dense tissues. The relative risk is greater than most traditional risk factors such as nulliparity and early menarche. This suggests therefore that there is a component of breast density that is independent of oestrogen mediated effects that may contribute to breast cancer oncogenesis.

There are several methods for measuring mammodensity; using qualitative and quantitative criteria by Wolfe's method ${ }^{2,6}$, BI-RADS classification ${ }^{7,8}$ and computer-assisted planimetry.

Mammographic Breast density patterns among Ugandan women is not documented. The objective of this study therefore was to assess and document mammographic breast density patterns among Ugandan women using the qualitative assessment method BIRAD classification to provide baseline data in this regard.

African Health Sciences Vol 12 Issue 4 December 2012 


\section{Methods}

A cross sectional descriptive study, enrolled consecutive women who were referred to the Radiology department at the National Referral Hospital in the Ugandan capital, Kampala for mammography. Its catchment area is the entire country but majority of the patients who come for screening are from the central part of Uganda due to easier geographical accessibility. The central part of the country is well represented by ethnic groups, age structure and socioeconomic status. A pre-tested questionnaire was used for data collection.

Mammographic breast density was categorised by the interpreting senior consultant radiologist. Each mammograph was read by one radiologist who applied BI-RADS categories: Almost entirely fat (1); Scattered fibro-glandular densities(2); Heterogeneously dense (3) and Extremely dense (4). Women with cancer were excluded so were those who has undergone previous surgeries or chemotherapy for breast disease. The cut off age for mammography was proposed to be 30 years according to a group of experts that put together the Ugandan treatment guidelines?. SSPS 11.5 was used for analysis. Frequency distributions of demographic characteristics and clinical risk factors were computed.

Ethical approval was obtained from the SoM

Research and Ethics Committee of Makerere University.

\section{Results}

Of the 190 patient enrolled over the 3 months study period, 178 were scored and had other relevant information obtained.

Table 1 : Clinical and demographic characteristics of the women that under went mammography

\begin{tabular}{lc}
\hline Characteristics & (n) \% \\
\hline Age & $45.8 \pm 12.5(190)$ \\
Ethnic groups & $70(39 \%)$ \\
Ganda & $15(8.5 \%)$ \\
Nkole & $13(7.5 \%)$ \\
Soga & $12(7 \%)$ \\
Kiga & $68(38 \%)$ \\
Others & $(178)$ \\
BI-RADS density & $78(41.1 \%)$ \\
Fat (Grade I) & $51(26.8 \%)$ \\
Scattered (Grade II)
\end{tabular}

Continuation of table 1

\begin{tabular}{lc}
\hline Characteristics & (n) \% \\
\hline Heterogeneous (Grade III) & $39(20.5 \%)$ \\
Extremely dense (Grade IV) & $10(5.3 \%)$ \\
Family history of breast cancer & \\
No & $165(86.8 \%)$ \\
Yes & $21(11.1 \%)$ \\
Menopause & $107(56.3 \%)$ \\
No & $83(43.7 \%)$ \\
Yes & $14.3 \pm 1.49(10-18)$ \\
Age at menarche & $5.1 \pm .1(1-16)$ \\
Number of pregnancies & $185(97.4 \%)^{*}$ \\
Non pregnant state & \\
\hline † First degree relative (Mother, sister or daughter) \\
with breast cancer \\
* 5 were missing values
\end{tabular}

\begin{tabular}{lc}
\hline Characteristics & \multicolumn{1}{c}{ Value (s) } \\
\hline Age: Mean & 38 years 3 months \\
& (SD \pm 12 years)
\end{tabular}

Family history of breast cancer ${ }^{\dagger}$ :

No 9

Yes

0

Missing value

1

Menopause:

No

$9(90 \%)$

Yes

$1(10 \%)$

Age at menarche: Mean

14 years 3 months ( $\mathrm{SD} \pm 2$ years)

Non-pregnant state

10

Number of pregnancies:

Mean

3.7

Range

$1-8$

Mammographic findings:

Benign lesions 7

Indeterminate 1

Suspicious 1

Missing value 1

\section{Discussion}

This study found that $25 \%$ of women in this study group had mammographic densities of grade III \& IV. Papers ${ }^{7-9}$ highlighting mammographic density studies in the USA and Europe reveal that the proportions of women with high mammographic densities of grades III \& IV are much higher up to three times what this study suggests. The caveat on this comparison is that in the Ugandan study group 
participants were 15 - 20 years younger and mostly pre menopausal compared to the studies found in literature.

However in this scenario we would have expected a higher portion of grades III \& IV mammo-densities in this young and premenopausal population, which wasn't the case. Possibly these low density scores imply relatively low exposure to estrogen despite low age and premenopausal status. Perhaps this could be validated by establishing circulating serum oestradiol levels in this population.

The clinical implications of this finding is that reading and interpretation of mammography films for breast related indications, may be easier since mammographic breast density is important predictor of accuracy of mammography as an investigative tool and secondly the cut off age for breast cancer screening for women (we currently follow $30-35$ years) should be revisited. High mammographic breast densities pose difficulties in interpretation, of films. Revisiting or revising the cut off age might increase the number of women eligible for screening mammography in this region, though this could be conclusively done in a larger population based study.

The mammodensiy distribution pattern in this study highlights yet another apparent epidemiological disparity between breast cancer among African women and their Caucasians counterparts ${ }^{10,11,12}$.

The women in this study with extremely dense breasts, (see table 2), were pre-menopausal, had a parity of 3.7 were not pregnant and not lactating. These factors are consistent with extremely dense breast pattern, apart from the parity of 3.7 which is on the higher side.

Although increased mammographic breast density is one of the strongest known risk factors for breast cancer ${ }^{13}$, little is known about why it is associated with breast cancer. The effect of oestrogen exposure does not account for it all.

Established breast cancer risk factors are associated with both increased and decreased Mammographic breast density. For example increasing age and menopause are independent contributors to the observed decrease in breast density that occurs with aging $^{2}$, pregnancy at an early age is associated with decreased breast density ${ }^{14}$. Other mechanisms therefore other than cumulative oestrogen exposure may account for the association of increased breast density and risk for breast cancer. Genes that determine breast density may also affect breast cancer growth factors that affect the breast have also been shown to be associated with mammographic density $^{2,15,16}$.

\section{Study limitations}

This study was not without limitations, the BMI was not considered in the analysis.

Most of the research work done on breast cancer in Uganda has been done at Makerere University Teaching hospital at Mulago. This facility provides comprehensive breast care services and is the referral center. Its catchment is country wide, it is plausible to generalize findings to entire population through a population based study in an asymptomatic patients would be more appropriate.

We used the standard BIRADS assessment of breast density by one study radiologist, who is very experienced, additionaly there is evidence that methods that quantify breast density may result in higher reproducibility and greater precision ${ }^{2}, 17$. So whereas using one reader who appear as a limitation, we urge it was not significant limitation in this study.

\section{Conclusion}

This study suggests that a large proportion of mammodensity is of low grade and possibly easier mammographic interpretation. This warrants revisiting the cut off age for screening mammography among this Ugandan by doing a population based mammodensity study. Having a large proportion of low grade mammodensity in comparison with studies in the more affluent nations suggests another epidemiological disparity between the races.

\section{References}

1. Kerlikowske K, Shepherd J, Creasman J, Tice AJ, Ziv E, Cummings SR. Are breast density and Bone Mineral density independent Risk factors for Breast Cancer? Journal of National Cancer Institute. 2005; 97(5): 368-374.

2. Boyd NF, Byng JW, Jong RA, Fishell EK, et al. Quantitative classification of mammographic densities and breast cancer risk: results from the Canadian National Breast Screening study. J Natl Cancer Inst. 1995; 87:67-5.

3. Harvey JA, Bovberg VE. Quantitative Assessment of Mammographic Breast Density: Relationship with Breast Cancer Risk. Radiology. 2004; 230: 29-41.

4. Freedman AN, Seminara D, Gail MH, Hartge $\mathrm{P}$, et al. Canacer risk predicyioon models: a 
workshop on development, evaluation and application. J Natl Cancer Inst. 2005; 97:715-23. (PMID 15900041)

5. Tice JF, Cummings SR, Smith-Bindman R, Ichikawa L, Barlow EW, Karlikowske K. Using Clinical factors and mammographic breast density to Estimate Breast cancer Risk: Development and Validation of a new predictive Model. Ann Inten Med. 2008; 148:337347.

6. Wolfe JN. Breast patterns as an index of risk for developing breast cancer. AJR AmJ Roentgenol. 1976; 126:1130-1139.

7. Lam PB, Vacek PM, Geller BM, Muss HB. The association of increased weight, body mass index, and tissue density with risk of breast carcinoma in Vermont. Cancer. 2000; 89:369-375

8. D’orsi CJ, Basset LW, Berg WA et al. Breast imaging Reporting data and Data system, mammography. $4^{\text {th }}$ ed. Reston, American Coll of Radiology; 2003.

9. Gakwaya A, Galukande M, Luwaga A, Jombwe J, Fualal J, Kiguli-Malwadde E, Baguma P, Kanyike A, Kigula-Mugambe JB. Breast Cancer guidelines for Uganda ( $2^{\text {nd }}$ Edition 2008). African Health Sciences. June 2008; Vol 8 N0 2: 126 -133.

10. Del Carmen M, Halpern EF, Kopans DB, Moy B et al. Mammographic Breast Density and Race. AJR 2007; 188: 147-1150

11. Newman ZA, Mason J, Cole D et al. AfricanAmerican ethnicity, socioeconomic status and breast cancer survival: a meta analysis of 14 studies involving over 10,000 African American and 40,000 White American patients with carcinoma of the breast. Cancer 2002; 94: 2844-2854

12. Gakwaya A, Kigula-Mugambe JB, Kavuma A, Luwaga A, Fualal J, Jombwe J, Galukande M and Kanyike D. Cancer of the breast: 5-year survival in a tertiary hospital in Uganda. British Journal of Cancer. 2008; 99: 63 - 67.

13. Prevrhal S, Shepherd JA, et al. Accuracy of mammographic breast density analysis: results of formal operator training. Cancer Epidemiol Biomakers Prev. 2002; 11: 1389-93.

14. Vachon CM, Kuni CC, Anderson VE, Sellers TA. Association of mammographically defined percent breast density with epidemiologic risk factors for breast cancer (United States). Cancer Causes Control. 2000; 11: 653 -62

15. Byrne C, Schairer C, Wolfe J et al. Mammographic features and breast Cancer risk; effects with time, age and menopause status. $J$ Natl cancer Inst 1995; 87: 1622 - 1629

16. Byng JW, Yaffe MJ, Jong RA et al. Analysis of mammographic density and breast cancer risk for digitised mammograms. Phys Med Biol. 1998; 43: 365-378

17. Lee-Han H, Cooke G, Boyd NF. Quntitive evaluation of mammographic densitie: a comparison of methods of assessment. Eur J Cancer Prev 1995; 4: 285-92 